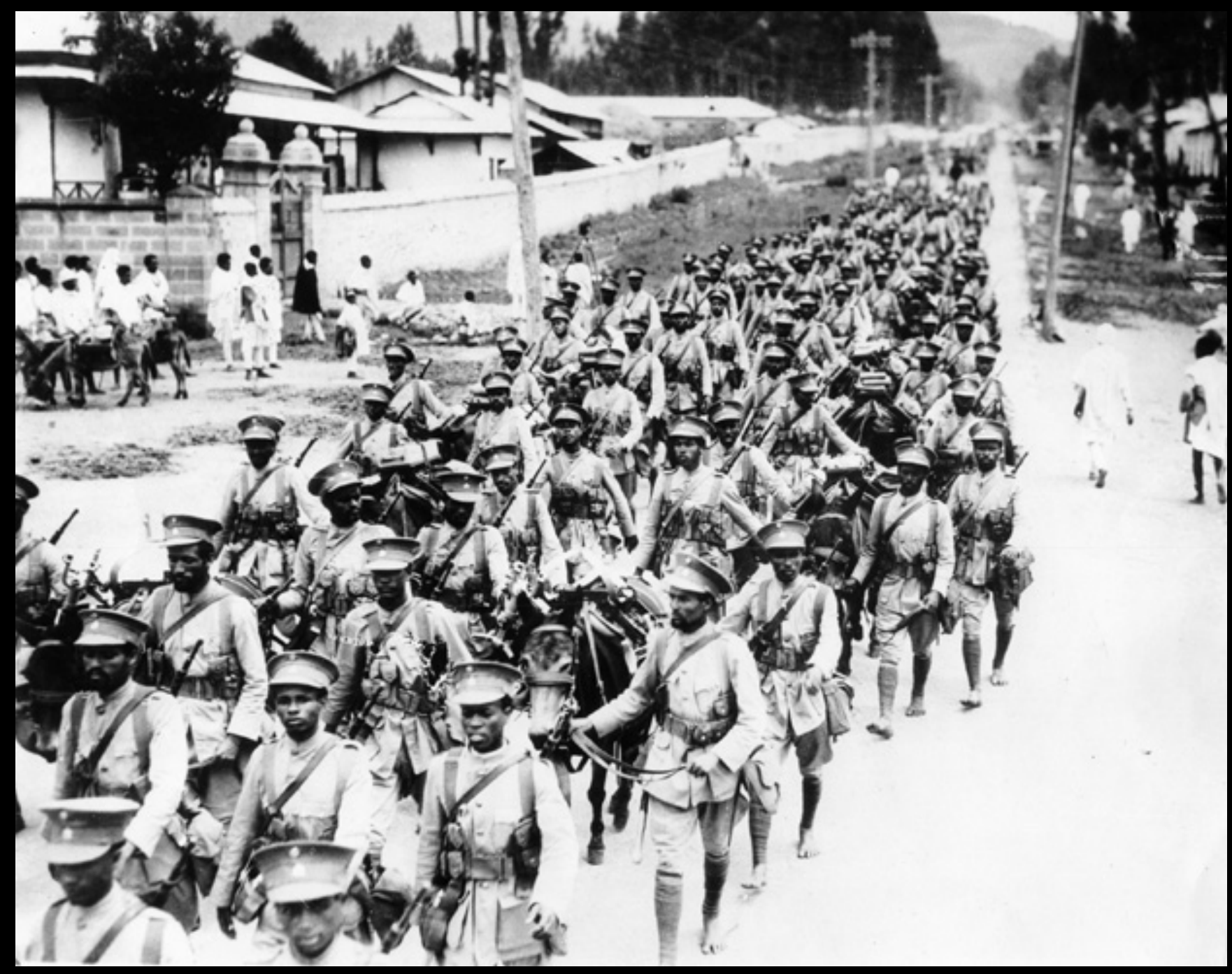

Ejército etíope marchando por las calles de Addis Abeba en vísperas de la agresión de la Revista Bohemia, Cuba, 1935 


\section{Cuba: el Diario de La Marina, los «misioneros de Mussolini» y la intelectualidad cubana proitaliana durante el segundo conflicto ítalo-abisinio (1935-1936) Cuba: Diario de La Marina, the "missionaries of Mussolini" and the pro-Italian Cuban intellectuals during the second Italo-Abyssinian conflict (1935-1936) \\ Cuba: Jornal dos Marines, os "missionários de Mussolini" e a intelectualidade cubana pró-italiana durante o segundo conflito ítalo-abissínio (1935-1936)}

Alberto Consuegra Sanfiel

Universidad de Buenos Aires

alconsaf@gmail.com

\section{Resumen}

El segundo conflicto ítalo-abisinio (19351936) desencadenó una fuerte polarización social a nivel mundial. Dentro y fuera del continente africano, Abisinia (actual Etiopía) encontró múltiples muestras de apoyo en defensa de su libertad y de respeto como Estado miembro de la Sociedad de Naciones desde 1923, mientras que en muchos lugares voces a favor del fascismo apoyaron la agresión armada. Este artículo hace un esbozo de los principales criterios esgrimidos por un reducido grupo de la intelectualidad cubana habanera comprometida con la emigración italiana profascista ya que resultó el ejemplo más cercano -no el más representativo- del apoyo que tuvo Mussolini en algunas naciones americanas.

\section{Abstract}

The Second Italo-Abyssinian conflict (19351936) triggered a strong social polarization worldwide. Inside and outside Africa, Abyssinia (now Ethiopia) found many expressions of support in defense of its freedom and displays of respect as a member state of the League of Nations since 1923 , while in many places voices in favor of fascism supported armed aggression. This article is an outline of the main criteria used by a small group of Havanan $\mathrm{Cu}^{-}$ ban intellectuals committed to the pro-fascist Italian emigration as it turned out to be the closest example -although not the most representative one- of the support Mussolini had in some American nations.

\section{Keywords}

fascism; Italy; Abyssinia; Cuba; press; support
E1 presente artículo es producto de la tesis «Mussolini contra Abisinia (1935-1936). Una cuestión que estremeció al mundo», presentada por el autor para optar al título de máster en Historia Contemporánea de la Universidad de la Habana.
Palabras clave

fascismo; Italia; Abisinia; Cuba; prensa; apoyo

\section{Resumo}

O segundo conflito ítalo-abissínio (19351936) desencadeou forte polarização social no nível mundial. Dentro e fora do continente africano, Abissínia (atual Etiópia) encontrou múltiplas demonstrações de apoio em defensa da sua liberdade e de respeito como Estado membro da Liga de Nações desde 1923, no entanto em muitos lugares, vozes em favor do fascismo apoiaram a agressão armada. Este artigo faz esboço dos principais critérios esgrimidos por uma turma reduzida da intelectualidade cubana havanesa engajada com a emigração italiana pró-fascista pois resultou o exemplo mais próximo -ainda que não o mais representativo- do apoio que Mussolini teve em algumas nações americanas.

\section{Palavras chave}

fascismo; Itália; Abissínia; Cuba; imprensa; apoio 


\section{Introducción}

La década de los treinta del siglo xx marcó el comienzo de una nueva época para las relaciones internacionales. Importantes acontecimientos, como el ascenso y consolidación de regímenes políticos autoritarios en Europa, el desarrollo de la Guerra Civil española, el progresivo ascenso del militarismo japonés en el continente asiático o el comienzo de la Segunda Guerra Mundial, son algunos de los fenómenos que casi siempre ilustran este decenio. Sin embargo, no pocos historiadores olvidan mencionar el conflicto entre Italia y Etiopía (1935-1936) a la hora de analizar este periodo.

Italia,luego de haber sido vencida en 1896 en la batalla de Adua, lanzó una nueva contienda militar contra el país africano con el objetivo de, aparte de explotar los supuestos recursos naturales que allí existían y de vengar-según los discursos pronunciados por Mussolini en nombre del pueblo italiano- la derrota sufrida, conquistar un territorio que permitiera darle el respiro económico que la dictadura fascista necesitaba, además de ganar prestigio internacional. Este hecho sellará el comienzo de una campaña mundial que, con importantes dirigentes panafricanistas al frente como George Padmore, Namdi Azikiwe, Wallace Johnson, Jomo Kenyatta, así como la posterior fundación del Buró Internacional Africano de Servicios al calor de la solidaridad con Abisinia en 1937, cambiará el destino de los pueblos africanos ${ }^{1}$.

Símbolo de la independencia y de la soberanía, la causa etíope halló fuera de África múltiples muestras de apoyo en defensa de su libertad y de respeto como Estado miembro de la Sociedad de Naciones desde 1923. La preparación de importantes manifestaciones públicas, la creación de asociaciones en defensa del pueblo africano o el envío de considerables sumas de dinero en apoyo a Abisinia, por citar algunos ejemplos, fueron varias de las reacciones que tuvo gran parte de la población en países como Estados Unidos, Francia, Inglaterra, etc. ${ }^{2}$

1 Armando Entralgo, África (Ciudad de La Habana: Editorial Pueblo y Educación, 1980), 103.

2 Hasta el momento no existe un trabajo que analice en su totalidad las variadas reacciones que tuvo gran parte de la población mun-
De igual forma, la personalidad del Duce y la conveniente imagen que supo vender al mundo de esta invasión, mostrándola como un gesto de humanidad en pos de librar al pueblo abisinio de la esclavitud y la incivilización, en países como Argentina, Hungría, Brasil y Cuba encontraron resonancia en algunos círculos de emigrados italianos o grupos de intelectuales. En ellos se encontró, indistintamente, el asidero perfecto para apoyar a Italia a través de mítines, artículos periodísticos, lanzamiento de proclamas o hasta con el alistamiento para formar parte de las tropas invasoras en la zona en disputa. Precisamente, el propósito de este trabajo es el análisis del impacto que provocó la agresión italiana a Abisinia en el plano de la política y de la sociedad cubana entre el 3 de octubre de 1935 (fecha en que se inicia la incursión) y el 9 de mayo 1936 (día en que se da a conocer al mundo la proclamación oficial de la Colonia de África Oriental Italiana con la unión de Eritrea, Somalia italiana y la ya conquistada Abisinia).

\section{El conflicto ítalo-abisinio (octubre, 1935-mayo, 1936)}

A diferencia del resto de las contiendas bélicas que se desencadenaron durante la década de los treinta del siglo pasado, dígase la Guerra Civil española o la Segunda Guerra Mundial, la invasión italiana a Etiopía constituyó una operación militar sui géneris. Primero, fue una guerra colonial atemporal que se desarrolló en un lapso de tiempo muy corto (aproximadamente siete meses), y segundo, fue una acción castrense en la que mucho antes de su comienzo se podía claramente predecir su vencedor debido a la superioridad

\footnotetext{
dial respecto a la guerra ítalo-etíope. En sentido general, estas estuvieron determinadas por razones disímiles. Para más información, consultar: Eugenia Scarzanella, «Cuando la patria llama: Italia en guerra y los inmigrantes italianos en Argentina», Nuevo Mundo Mundos Nuevos. http://nuevomundo.revues.org/3735 (consultado en enero de 2014). M. Yu Frenkel, «Italo-Ethiopian War of 1935-1936 and the attitude to it of the progressive European public (as reflected in the journal 'Negro Worker'», en Anticolonialism and democratic traditions in Europe: African Aspect (Bratislava: Institute of Historical Studies of the Slovak Academy of Sciences, 1985), 148. Jesús Albert, «Las relaciones entre los fascismos y el movimiento nacionalista árabe», Revista de Estudios Internacionales Mediterráneos (REIM), n. 6 (2008): 53-77.
} 
visible y palpable que portaba la nación europea en cuanto a armamento moderno y municiones.

Oficialmente, los choques armados a gran escala entre los tropas regulares de ambos países, cuyo accionar legalmente enmarcan el desarrollo de la conflagración, se iniciaron el 3 de octubre de 1935 y culminaron el 5 de mayo de 1936 con la toma de Addis Abeba. Sin embargo, para muchos seguidores del tema, los imprevistos y oportunos incidentes fronterizos que se iniciaron en diciembre de 1934 y que se extendieron durante los primeros seis meses de 1935 son en ocasiones considerados el inicio de las maniobras militares.

E1 5 de diciembre de 1934, mientras una comisión mixta anglo-etíope se encargaba de llevar a cabo la delimitación de fronteras entre el Somaliland británico y el Ogadén etíope, exactamente en el oasis de Walwal, el destacamento etíope encargado de la protección de dicha comisión entró en combate con un destacamento italiano, convirtiéndose así este incidente fronterizo en el casus belli $^{3}$ de la futura guerra ${ }^{4}$. Este exabrupto, provocado o no, abrió la lista de un sinnúmero de choques a todo lo largo de la frontera, los cuales fueron agravando progresivamente la situación hasta hacer desencadenar la embestida final, llegando a involucrar a gobiernos vecinos ajenos a la controversia, como, por ejemplo, el francés 5 .

Durante los meses de enero a octubre de $1935 \mathrm{el}$ alto mando militar italiano se encargó de preparar y mover hacia las colonias vecinas de Eritrea y la Somalia italiana toda la logística necesaria que supuestamente requeriría para atacar, mientras que en la Liga de las Naciones el representante italiano, portavoz del Primer Ministro, informaba que las negociaciones con Haile Selassié marchaban a todo ritmo y positivamente.

3 Concepto proveniente del latín para nombrar el caso o el motivo de una guerra (Nota del autor).

4 Según informes de Roma, en esta batalla perecieron treinta soldados italianos y 110 etiópicos. Eduardo Ortega y Gasset, Etiopía: el conflicto Ítalo-Abisinio (Madrid: Imprenta de Juan Pueyo, 1935), 170.

5 El 21 de enero de 1935, 107 personas, con inclusión de un funcionario francés de administración, murieron asesinados en Djiboutí como parte de un raid perpetrado, supuestamente, por tribus salvajes del interior de Etiopía. Esta masacre despertó un inusitado interés a causa del reciente incidente de Walwal acaecido en el mes de diciembre, y se manejó la idea de que varios gobiernos, sobre todo el etíope, podían haber tenido responsabilidades en el asunto. Tomado de: EFE, «Muerte a un funcionario colonial francés en Djiboutí», Diario de La Marina [La Habana], 22 de enero, 1935, 22.
Paralelamente, rotativos importantes estrechamente vinculados a la maquinaria propagandística del régimen fascista, como el periódico Giornale D'Italia o La Force Armate ${ }^{6}$, daban a conocer cifras y datos referentes a los preparativos con vista a la contienda que objetaban por completo las propias declaraciones oficiales emitidas por Roma ${ }^{7}$.

Se calcula que Mussolini llegó a acuartelar en tierras africanas más de medio millón de italianos antes de octubre, quienes en su mayoría provenían de las interminables listas de desempleados censados por los gobiernos provinciales y el número de conscriptos era significativo dentro la gran masa de soldados. Las primeras unidades llegadas a África respondían, como si fueran legiones romanas, a nombres como Gavinana, Peloritana, Sabauda, mientras las divisiones de Camisas Negras se llamaban según las fechas importantes del calendario fascista ${ }^{8}$.

Por su parte, las tropas del Negus ascendían pobremente a la cifra de 350 mil hombres y, aunque habían sido formadas y entrenadas por extranjeros, las carencias materiales que tenían impedían que el ejército hamítico se pudiese comparar con el alto nivel alcanzado por cualquier ejército europeo, incluyendo el italiano. La situación del armamento era una de las limitantes mayores que debieron enfrentar. Con apenas 40.000 fusiles de diversos tipos, el alto mando etíope se vio, sobre todo durante el periodo prebélico, privado de encontrar cartuchos debido a la variedad y los diversos tipos de calibres que necesitaban. De igual forma, las más de 200 piezas de artillería que poseían estaban montadas sobre cureñas rígidas, lo que imposibilitaba cualquier movimiento rápido sobre el terreno, además de

6 Publicación semioficial del Departamento de la Guerra italiano en esa época (Nota del autor).

7 Todo el tiempo que duró el proceso de «negociaciones» (eneroseptiembre), el representante italiano ante la Liga de las Naciones, barón Aloisi, estuvo haciendo declaraciones de prensa alentadoras acerca de las conversaciones entre ambos países. A modo de contraataque, el Encargado de Negocio etíope en Roma, Negradas Yessus, desmintió una y otra vez el contenido de estas, afirmando que «[...] Italia continúa con los preparativos bélicos en sus colonias y que Etiopía está resuelta a defenderse contra cualquier agresor [...]》. EFE, «Niegan avance en las negociaciones entre Italia y Abisinia», Diario de La Marina [La Habana] 14 de abril, 1935, 7.

8 Michael Alpert, «La conquista de Abisinia», Historia 16, n. 354 (2005): 40. 
que el puñado de aviones que conservaban incluía biplanos Potez sin pertrechos que tendrían que enfrentarse contra lo más moderno de la Regia Aeronáutica9.

Firmes y seguras en las colonias de Eritrea y Somalia, en la madrugada del 3 de octubre de 1935 las tropas italianas irrumpieron en territorio etíope exactamente por un punto fronterizo entre la Somalia francesa y Eritrea, justo al sur de las elevaciones del Mussa Alí. Ese mismo día, Hailé Selassié envió una nota de protesta dirigida a $\mathrm{Gi}^{-}$ nebra con motivo de la acción a través de la cual se informaba al mundo lo siguiente:

[...] Informamos a usted para que lo traslade al Consejo y a los estados que pertenecen a la Liga, que las tropas italianas han violado la frontera etiópica en la región del sur del Monte Mussa Alí, provincia de Aussá, entre esa montaña y la frontera de Etiopía y el Somal francés $[\ldots]^{10}$.

Iniciada de esa manera la guerra, los meses venideros estuvieron signados por un constante avance de las tropas italianas. Sin embargo, la táctica de pacificación empleada en un primer momento por el general Emilio De Bono, así como el temor que tenía de alargar demasiado sus líneas de comunicación y de caer en una trampa, resultó ser una estrategia que permitió maniobrar con cierto éxito a las tropas etíopes del norte, algo que no toleró el Primer Ministro quien exigía desde el inicio un triunfo fulminante. A pocas semanas de haber iniciado las acciones castrenses, De Bono fue sustituido por el mariscal Pietro Badoglio quien, a partir de entonces, empleó en el terreno de lucha todos los métodos que tuvo a su alcance con el objetivo de satisfacer a Mussolini en su deseo por destruir totalmente a las tropas enemigas.

Aunque en un principio los centenares de miles de soldados y milicianos italianos que tomaban parte en la llamada conquista del imperio no pudieron dar a aquella empresa un juicio negativo, en la medida que pasaron los meses la moral y el ánimo de las tropas invasoras, así como su

9 Alpert, «La conquista de Abisinia», 40.

10 EFE, «Diez millones de hombres, mujeres y niños acudirán prestos a la llamada tradicional en defensa de la Patria», Diario de la Marina [La Habana], 3 de octubre, 1935, 22. percepción de la contienda, tuvo que ser constantemente fortalecida por los medios propagandísticos del régimen debido a la propagación de epidemias típicas de la región, además de que la agresividad del relieve provocó una extenuación generalizada en las huestes. No obstante, la inesperada ineficacia mostrada por los efectivos de tierra fue suplantada por el accionar y efectividad de la aviación, sin la cual, se puede afirmar, no hubiesen vencido.

El Estado Mayor italiano puso en práctica a cabalidad la hipótesis durante la guerra en Etiopía de la utilización masiva de bombardeos como opción estratégica y decisiva para la victoria final, esgrimida y desarrollada por algunos militares como el italiano Guilio Dohuet o el norteamericano Billy Mitchell en la década de los veinte. A partir de noviembre de 1935, el avance italiano se vio fuertemente amenazado por el accionar y los exiguos conocimientos militares de cuatros jefes tribales quienes hicieron retroceder al ejército del mariscal Badoglio cerca de la frontera con Eritrea, situación que obligó al alto mando a arreciar los bombardeos, además de conjugarlos con el uso de iperita o gas mostaza ${ }^{11}$.

Dada la orden, el 23 de diciembre del propio año, los aviones fascistas hicieron acto de presencia encima de los campamentos etíopes, incluyendo los de la población civil y los edificios supuestamente protegidos de la Cruz Roja, y comenzaron a arrojar ininterrumpidamente contenedores de la sustancia tóxica; al impactar contra el suelo o al caer en las aguas de los ríos, estos expandían un líquido incoloro el cual provocaba en los abisinios sendas quemaduras y ampollas en las partes desnudas de sus cuerpos ${ }^{12}$. Aunque los datos son muy imprecisos, se calcula que la aviación italiana arrojó de diciembre de 1935 a abril

\footnotetext{
11 Conocido ya por su utilización en la Primera Guerra Mundial, se trata de un vesicante que produce afectaciones características como ampollas y quemaduras en la piel, con graves consecuencias para las personas no protegidas. En el momento de la utilización de este agente químico, Italia, junto a 40 Estados más, era signatario del «Protocolo de Ginebra sobre la prohibición del empleo en la guerra de gases asfixiantes, tóxicos o similares y de medios bacteriológicos», lo que indica que cometía una violación del derecho internacional. Rainer Baudendistel, «La fuerza frente al derecho: el Comité Internacional de la Cruz Roja y la guerra química en el conflicto ítalo-etíope de 1935-1936», Revista Internacional de la Cruz Roja, n. ${ }^{145,}$ (1998): 90.

12 Alpert, «La conquista de Abisinia», 46.
} 
de 1936 aproximadamente un total de 330 toneladas de agentes químicos, provocando así la muerte de un sinnúmero de guerreros y civiles ${ }^{13}$.

Esta manera de hacer guerra empleada por Italia potenció aún más la superioridad de su ejército en comparación con el abisinio, y catalizó sin lugar a dudas la llegada de la victoria a sus manos. Además de conseguir infundir en los valerosos soldados africanos el miedo y el terror, la presencia casi a diario de los bombarderos Caproni Ca-101 afectó la moral de los abisinios, quienes, carentes de equipos especializados para responder a los ataques tóxicos y sin la atención médica adecuada que al menos les hubiese permitido mitigar las secuelas como demostró la experiencia a finales de la Primera Guerra Mundial, en muchas ocasiones prefirieron correr el riesgo de ser capturados como desertores antes de morir en tales circunstancias de dolor ${ }^{14}$.

Es importante destacar que la organización del sistema de emergencias durante la guerra en territorio etíope era insuficiente para la cantidad de población que día a día caía herida u afectada. Con solo 12 hospitales de campaña de la Cruz Roja y un número reducido de empleados, en su mayoría europeos y norteamericanos, las posibilidades reales de cubrir con eficacia las necesidades sanitarias de la población abisinia eran muy pocas. De igual forma, cabe tener en cuenta que el arribo de sanitarios y especialistas en los frentes de batalla solo se logró casi al terminar la guerra, aparte de que en el noventa por ciento del tiempo que duró la guerra química el acceso a una asistencia hospitalaria adecuada y moderna fue muy limitado o inexistente ${ }^{15}$.

Debilitadas progresivamente sus fuerzas, el ejército del Negus fue cediendo cada vez más terreno hasta llegar a concentrarse en Addis Abeba, ciudad en donde las columnas mecanizadas de Badoglio hicieron su entrada triunfal el 5 de mayo de 1936. Cuatro días después, el Duce proclamó el Imperio

13 Baudendistel, «La fuerza frente al derecho», 91.

14 Baudendistel, «La fuerza frente al derecho», 91.

15 Casi todos los miembros de la Cruz Roja que se encontraban asistiendo en el país eran extranjeros y tenían como tarea, además de coordinar las actividades de los hospitales de campaña de la organización, el adiestramiento del personal de la Cruz Roja local, filial que se había fundado solo tres meses antes. Baudendistel, «La fuerza frente al derecho», 92. de África Oriental ante la multitud delirante que llenaba la Plaza Venecia, estatus que mantuvo Etiopía hasta 1941 cuando las tropas aliadas permitieron el regreso de su Emperador Hailé Selassié y con él la restauración de la monarquía.

\section{Ecos de un conflicto}

A lo largo de los casi siete meses que duraron las acciones bélicas en Etiopía - a diferencia de lo ocurrido en otros países como Estados Unidos, Argentina, México o Europa-, la sociedad cubana en sentido general no mostró mucho interés por lo que aconteció en África. Durante el primer lustro de la década del treinta del siglo pasado la mayoría de la población del país se mantuvo desconectada de los acontecimientos internacionales debido a los efectos de la Gran Depresión de 1929-33 y el ineficiente mandato de Gerardo Machado (1925-1933). Sumergida aún en una profunda crisis económica y estremecida, además, por la gran estampida social que terminó con el «Machadato» ${ }^{16}$, los círculos de opinión de la isla centraron toda su atención en la búsqueda de soluciones personales inmediatas relacionadas con la estabilidad y el bienestar económico.

Si bien el fin de la Primera Guerra Mundial y la «danza de los millones» había traído consigo el nacimiento de nuevas e importantes urbanizaciones, sobre todo en La Habana, es importante destacar que Cuba era también una nación de contrastes y de grandes masas marginadas, donde la población rural, en un país básicamente agrícola, tenía un gran peso y vivió, casi hasta mediados de los años sesenta, al margen del propio acontecer político nacional, tanto de la cuestiones culturales, como de las noticias extranjeras que por esta época llegaban a las ciudades. Según los datos arrojados por el Censo Electoral de 1931, el 48,6\% de la población se consideraba «población rural» y era la capital, seguida por la región de Matanzas y Oriente, la zona que mayor proporción de habitantes concentraba ${ }^{17}$. Sin

16 Por lo general con este nombre se le llama al periodo histórico en Cuba que va de 1925 a 1933, en honor al presidente de esos años, Gerardo Machado y Morales (Nota del autor).

17 Francisca López Civeira, «El cambio histórico», en Cuba y su historia (Ciudad de La Habana: Editorial Félix Varela, 2005), 162. 
embargo, en ninguna de estas urbes se organizaron manifestaciones y actos públicos a favor ni en contra de la causa etíope.

A pesar de esto no se puede plantear categóricamente que la invasión de Italia a Abisinia pasó desapercibida. La sociedad cubana, acostumbrada a polemizar y a cuestionar el acontecer mundial, no ignoró por completo la articulación y desarrollo de la agresión y puede afirmarse que, en general, los residentes urbanos y, más específicamente, la intelectualidad habanera no permaneció ajena del todo a los ecos de la disputa. De hecho, quizás la mejor forma de medir, reconstruir y modelar al menos parcialmente el grado de impacto y los alineamientos asumidos en Cuba es a través del examen de los medios de prensa escritos, plataforma por excelencia de las opiniones respecto al conflicto.

Aunque hubo publicaciones y voces que se manifestaron en contra del fascismo y a favor del país agredido $^{18}$, poco a poco estas fueron cediendo terreno a sus contrarios y, aun cuando sus apreciaciones fueron las más justas y atinadas, los más difundidos fueron los juicios favorables a Roma. La solvencia económica que disfrutó la emigración fiel a Italia, al igual que la de los cubanos que la secundó, facilitó el acceso a poderosos espacios de comunicación de la época que divulgaron con fuerza las opiniones y criterios que ellos esgrimían. Como consecuencia directa, fueron estas prácticamente las únicas apreciaciones que sobrevivieron al paso del tiempo y llegaron hasta nuestros días.

Al igual que en casi todos los países latinoamericanos que contaban al momento del acontecimiento con una colonia italiana organizada, en Cuba el conflicto halló seguidores en un reducido grupo de italianos profascistas asentados en la

18 La Sociedad Club Atenas y el Círculo Español Socialista protagonizaron los pocos actos que se organizaron en Cuba para repudiar la agresión. No obstante, estos encuentros no tuvieron mucho alcance pues fueron diseñados para sus afiliados y en espacios que no fueron más allá de sus sedes. De igual forma, el Comité Distrital de La Habana del Partido Comunista desarrolló una incipiente actividad propagandística en contra de Italia. Para más información, ver: Editorial, «Un acto cívico a favor de Abisinia en el Club Atenas», Diario de La Marina [La Habana], 5 de noviembre, 1935, 3; Editorial, «Sociedades Españolas», Diario de La Marina [La Habana], 19 de febrero, 1936, 8; Archivo Nacional de Cuba, «Manifiesto impreso del Partido Comunista de Cuba, firmado por el Comité Central referente al ataque del imperialismo italiano al pueblo abisinio», Fondo Especial, Legajo 1, Expediente 53. capital de la isla. Ellos, con autoridad en la prensa más influyente del momento, específicamente en el periódico habanero Diario de La Marina, se aliaron a un exiguo grupo de intelectuales e hicieron de este medio de comunicación su principal vía de apoyo a Italia.

Sin lugar a dudas, el quehacer propagandístico a favor de la potencia agresora que llevó a cabo este grupo profascista durante los meses que duró la conquista de Etiopía estaba indisolublemente ligado a algunas de las directrices que en política exterior aplicó Mussolini para el continente latinoamericano. Desde la década de los veinte, el Primer Ministro trató de extender hacia América Latina su influencia y su prestigio presentando al fascismo, en la voz de importantes y pudientes figuras dentro de la inmigración italiana asentada en los diferentes países, como un modelo político y cultural alternativo, en cuanto «tercera vía» entre bolchevismo y el liberalismo; lo introdujo, además, como competidor en el ámbito del juego de influencias norteamericanas, británicas, alemanas y españolas, por la hegemonía del área ${ }^{19}$.

Realmente la acción concreta de la política italiana hacia el continente fue variable en tiempos y espacios. A partir de los hechos, parece evidente una intensificación de las actividades políticas y culturales encaminadas a América en la década de 1930 con el objetivo de buscar apoyo efectivo durante el conflicto etiópico y luego con la Guerra Civil Española. Respecto al impacto geográfico, se puede hablar, más propiamente, de políticas dirigidas a cada país, destacándose aquellos de mayor importancia como Brasil, Argentina, Uruguay y México, por ser zonas receptoras de emigración italiana masiva. Unido a esto, luego de la crisis mundial y aprovechando la profunda sacudida del orden internacional, América Latina adquirió especial interés para Roma pues era la única área que no estaba bajo la dominación directa de las grandes potencias europeas, siendo, al mismo tiempo, rica en recursos ${ }^{20}$.

En el caso de Cuba, en 1935, había en el país unos 1178 italianos y de ellos 762 -más de la

\footnotetext{
19 Franco Savarino, «Apuntes sobre el fascismo italiano en América Latina (1922-1940)», Reflejos, n. 9 (2000-2001): 103.

20 Savarino, «Apuntes sobre el fascismo», 105.
} 
mitad- residían de manera permanente en La Habana $^{21}$. De acuerdo con la ínfima presencia italiana, es manifiesto que la isla no clasificaba como área prioritaria dentro de la agenda exterior fascista si consideramos el número de inmigrantes que habían llegado históricamente desde el país europeo, por ejemplo, al Cono Sur ${ }^{22}$. Sin embargo, según los resultados arrojados por un estudio que hiciera el Dr. Emilio Núñez Portuondo, profesor de Derecho Civil y Derecho Público de la Universidad de La Habana, a solicitud del embajador italiano en la capital, $\mathrm{Sr}$. Nicola $\mathrm{Macario}^{23}$, la situación geográfica de Cuba era vital para cualquier labor de propaganda escrita $u$ oral que pensase hacer el gobierno de Italia respecto a América ${ }^{24}$. Precisamente fue este factor el que hizo posible que La Habana se convirtiera, durante la década de los treinta en el centro irradiador por excelencia de las ideas fascistas que llegaban desde Roma, sirviendo, además, como cuartel a un selecto grupo de fascistas italianos que vieron en la invasión a Abisinia un momento oportuno para expresar sus sentimientos e intensificar su labor proselitista.

En consonancia con esto, es importante destacar que uno de los primeros efectos que tuvo la victoria fascista en 1922 para América Latina fue la formación de secciones del Partido Fascista (Fasci) en varios países del área, no siendo Cuba una excepción. Los «Fasci» eran la manifestación clara del fuerte impulso hacia el exterior que desde un inicio se planteó el gobierno italiano. Tenían dentro de sus objetivos esenciales organizar las comunidades emigradas, asistir a los italianos, y vigilar e informar el desarrollo de los grupos antifascistas («fuoriusciti»), mientras que a su vez las funciones políticas más importantes eran encargadas directamente a las legaciones en cada

21 Oficinal Nacional de Estadísticas, Cuba, Los censos de población y viviendas en Cuba. Censos del periodo 1907-1953 (Ciudad de La Habana: Oficinal Nacional de Estadísticas, 2007), 280.

22 En 1928 el Ministerio de Relaciones Exteriores de Italia calculaba un total de 3.803.902 italianos residentes en América Latina, casi todos concentrados en Brasil (1.839.579) y en Argentina (1.797.000). Savarino, «Apuntes sobre el fascismo», 106.

23 Nicola Macario estuvo como Ministro Plenipotenciario del Reino de Italia en Cuba desde 1934 a 1937. Anuario Diplomático y Consular de la República de Cuba (vir) (La Habana: Cultural S.A, 1940), 470.

24 Para más información, consultar: Froilán González y Adys Cupull. Julio Antonio Mella y Tina Modotti contra el Fascismo (Ciudad de La Habana: Casa Editora Abril, 2005), 182. país ${ }^{25}$. En el caso del que se fundó en La Habana en los años veinte, además de los propósitos generales antes planteados, la tarea más importante que tenía a su cargo era la de divulgar con fuerza en Cuba y desde Cuba las ideas fascistas en la búsqueda de simpatías ${ }^{26}$.

De hecho, durante el conflicto ítalo-etiópico los italianos asentados en la isla y los periodistas cubanos, que aplaudieron desde las páginas del rotativo Diario de La Marina la política expansiva que llevó a cabo Italia en África durante 1935-1936, formaban parte del Fascio habanero o colaboraban estrechamente con él. Sin embargo, este comportamiento no representó un hecho natural y espontáneo. La labor de defensa y exaltación que se llevó a cabo desde Latinoamérica a favor del gobierno de Roma, y en especial desde Cuba, formó parte del plan que trazó el Primer Ministro fascista con vistas a contrarrestar el boicot internacional que sufrió su país a causa de la invasión a Etiopía, y los elegidos para desempeñar esta tarea fueron los emigrados seguidores de sus ideas.

Por otra parte, la utilización del mencionado órgano de prensa habanero por parte de los discípulos de Mussolini asentados en Cuba, quienes expresaron a través de sus páginas el «patriotismo emotivo» que decían sentir respecto a Italia, no fue tampoco un hecho al azar. Sin lugar a dudas, el Diario, desde su fundación en el siglo xIx hasta su cierre en 1960, fue uno de los periódicos más influyente y leídos por toda la población, además de que su carácter conservador lo convirtió en el portavoz perfecto de las apreciaciones y puntos de vistas de la derecha cubana e italiana establecida en la isla. De igual forma, sus páginas siguieron minuto a minuto, desde mucho antes de octubre de 1935 , los preparativos militares, las posiciones internacionales de algunos países, y la evolución del conflicto hasta que llegó a su fin, ofreciendo una mayor cobertura del suceso en comparación con otros suplementos informativos.

La columna «Actualidad Internacional», la cual estaba a cargo del periodista Juan Luis Martín, fue

25 Para 1929, en toda América, incluyendo a Estados Unidos y Canadá, se estima que hubieron cerca de 210 Fasci. Savarino, «Apuntes sobre el fascismo», 107.

26 En el Archivo Nacional de Cuba no existen fondos de dicha organización (Nota del autor). 
una de las secciones que ininterrumpidamente siguió de cerca la cuestión ítalo-etíope. Esta página, como su nombre lo indica, estaba dedicada al análisis de los acontecimientos internacionales de mayor envergadura de la época y, por lo general, era cubierta solo por los comentarios de su responsable editorial. Si bien en ocasiones se publicaron algunos artículos de muchos de sus colegas, estos nunca hicieron variar la acostumbrada manera conservadora de enfocar los fenómenos que se examinaban. En relación con la disputa euro-africana, «Actualidad Internacional» siempre mantuvo un carácter favorecedor con Italia y los análisis que sacó a la luz tuvieron invariablemente los siguientes objetivos: exaltar la labor del gobierno fascista, desacreditar la situación interna de Etiopía como país independiente, y reprochar la labor de la Gran Bretaña y de la Sociedad de Naciones en su mediación en el conflicto.

Justamente, cuando en mayo de 1935 Roma movilizaba aceleradamente los efectivos que necesitaría para ocupar Abisinia y la labor propagandística del régimen fascista era desmedida a fin de justificar sus actos, el corresponsal Tiburcio Castañeda publicó en dicha columna un comentario titulado: «Italia despliega actualmente una gran actividad guerrera». En apenas pocos párrafos, el autor se refirió al arduo trabajo que hacían las fábricas de municiones de la sección industrial de Milán con el objetivo de abastecer al ejército que muy pronto se enfrentaría con las desvalidas huestes abisinias. Al cierre de la nota encumbró al pueblo italiano y a su líder al alegar que:

[...] Italia ha demostrado, como una nación con rapidez que no era rica, como ella se puede desarrollar industrialmente, disminuyendo las exportaciones y sufriendo los efectos de una guerra monetaria, cuyos industriales la consideran de gran prejuicio para la economía y para su noble pueblo $[\ldots]^{27}$.

Uno de los aspectos recurrentemente tratados por Juan Luis Martín en su sección fue la situación política interna de Etiopía, así como el «falso odio» que mantuvo el gobierno etíope respecto a Italia

27 Tiburcio Castañeda, «Italia despliega actualmente una actividad guerrera», Diario de La Marina [La Habana], 7 de mayo, 1935, 20. y a sus nacionales después de Adua ${ }^{28}$. Haciendo recurrentemente sinuosos bosquejos históricos de las relaciones entre ambos países, es evidente que el periodista cubano secundó sin reparos en varios de sus comentarios la opinión de Mussolini, quien en más de una ocasión había afirmado, rebatiendo algunas declaraciones públicas de Hailé Selassié, que en Abisinia se cultivaba la fobia contra los italianos. Según Martín, en un artículo publicado el 6 de julio de 1935, las afirmaciones del Emperador no eran sinceras, y escribió:

[...] Los etíopes pretenden ser un pueblo viril, conquistador, y los timbres de la actual dinastía nacen precisamente en Adua, en que creyeron haber demostrado que Italia era inferior a Etiopía. El prestigio italiano se ha mermado enormemente a causa de esa derrota y ni aún los salesianos con sus establecimientos culturales, ni los médicos italianos que han construido modernísimos hospitales allí, han logrado convencer a los etíopes que no fue por cobardía ni por inferioridad, sino por el desgobierno que reinaba en Italia del último tercio del siglo pasado. El desprecio constante que se profesa a los italianos, la afrenta continuada, son también una manifestación de odio. Mussolini, por otra parte, sabe que actualmente se aprecia más a un griego en Abisinia que a uno de sus compatriotas ${ }^{29}$.

También las distintas propuestas de paz que Inglaterra y Francia presentaron en repetidas ocasiones al Duce, a nombre del organismo internacional ginebrino, fueron motivo de críticas y de sarcasmo por parte del mencionado intelectual. En agosto de 1935, en ocasión de celebrarse la Conferencia Tripartita ${ }^{30}$ en la que se le ofreció a Roma

28 Combate que tuvo lugar en Adua, en la zona norte de la actual Etiopía, el 1 de marzo de 1896, y que finalizó con la derrota de una fuerza de invasión italiana a manos de las fuerzas leales al emperador Menelik II. Puede considerarse como la más importante victoria africana frente a un ejército de la época colonial, gracias a la cual Etiopía mantuvo su independencia. Para más información consultar: Pierre Bertaux, África, desde la prehistoria hasta los Estados actuales. Historia Universal Siglo XXI (Madrid: Ediciones Castilla, S.A., 1972), 184-185.

29 Juan Luis Martín, «Actualidad Internacional», Diario de La Marina [La Habana], 6 de julio, 1935, 22.

30 La «Conferencia Tripartita» fue uno de los tantos intentos que realizaron Inglaterra, Francia y la Sociedad de Naciones con el fin de frenar los intentos expansionistas de Italia sobre Etiopía. Esta reunión se celebró en París el 16 de agosto de 1935 con el objetivo de llegar a un acuerdo. A groso modo, las propuestas hechas propiamente por Francia eran las siguientes: Francia e Inglaterra renunciarían a todo privilegio económico en beneficio de Italia, se le concedería un empréstito al gobierno de Roma para realizar inversiones de carácter económico en el país africano con la posibilidad de explotar en toda su intensidad los recursos naturales del país, y por último, Mussolini gozaría de ciertos derechos políticos 
la posibilidad de crear un protectorado de la Sociedad de Naciones donde Italia tendría la primacía económica y política, salió a la palestra un extenso artículo en el diario, firmado por él, en el que atacó abiertamente el papel que Inglaterra y Francia estaban desempeñando como mediadoras en el conflicto y, una vez más, se refirió, con un desprecio inconmensurable, a la inferioridad que para él tenía el pueblo etíope al agregar:

[...] Se pretende imponer a los etíopes el protectorado de la Sociedad de Naciones con lo cual la situación que Abisinia anhela evitar se producirá de cualquier manera. ¿Qué más da al Negus Hailé Selassié que su tierra sea una dependencia de la Sociedad de Naciones que de Italia, con las mismas restricciones para la soberanía abisinia? [...] Cerca de Abisinia se ha estado haciendo últimamente una propaganda interesada que trata de hacernos ver que el antiquísimo estado africano es una perfección política, que puede medirse de igual a igual con cualquier potencia occidental. La mano británica se deja ver en estos hechos [...]. Abisinia no ha creado una civilización. No conserva la de Egipto, no asimiló la de Grecia, no aprovechó los valores del cristianismo ni adoptó los del musulmanísmo. En África han existido potentes imperios negros, de civilización más sólida que la etiópica (y quizás nacida en el mismo tronco que ella), que ha sido destrozada por Inglaterra y Francia ${ }^{31}$.

Sin embargo, uno de los hechos que de manera clara y abierta nos permite definir mejor los principios editoriales que mantuvo el Diario de la Marina en relación con el conflicto es el análisis de los artículos que publicó la sección «Columna Editorial» - o «Impresiones», como también se le tituló en varios números-, la cual era un sitio reservado exclusivamente para los comentarios y puntos de vista del director del rotativo, José Ignacio Rivero. Si bien es cierto que solo dedicó al conflicto tres artículos, es importante destacar que el menosprecio que sentía por todos aquellos que se oponían a la agresión y su apoyo a las ideas del fascismo italiano fue desde un inicio perceptible en sus trabajos.

E1 5 de septiembre de 1935 salió publicado su primer escrito. Con un lenguaje poético y haciendo

mediante el nombramiento de consejeros técnicos y directores de aduana. EFE, «Las gestiones fracasarán en caso de no llegarse a un acuerdo durante la semana entrante, según ingleses», Diario de La Marina [La Habana], 18 de agosto, 1935, 28.

31 Juan Luis Martín, «Actualidad Internacional», Diario de La Marina [La Habana], 6 de agosto, 1935, 22. gala de sus excelentes dotes periodísticas, José Ignacio desde el principio hasta el final dedicó su comentario a hacer un estudio de las necesidades económicas que obligaban a Italia a mantener una actitud guerrera frente al imperio africano. La utilización de frases como «la gloriosa nación latina», «estos son tiempos de Doña Necesidad», o «Mussolini está cansado de las befas del León», son elementos que demuestran una total coincidencia entre las ideas manejadas por él y las insuficiencias materiales que esgrimió el régimen de Roma para justificar la invasión ${ }^{32}$.

El día 3 de octubre, cuando se inició el avance de las tropas italianas sobre territorio abisinio, publicó un segundo artículo, en el cual, con un carácter aparentemente inofensivo, expuso las consecuencias nefastas que podría traer para la paz internacional, como indicaba su título, «El paso dado por Italia». En pocas palabras, el director sutilmente arremetió contra la Sociedad de Naciones al decir:

A lo que parece, va a quedar demostrada una vez más la inutilidad de la Sociedad de Naciones para la protección de los pueblos débiles, y la ineficacia de los tratados que los garantizan contra las agresiones de los pueblos fuertes y necesitados como el de Italia $[\ldots]^{33}$.

Su último trabajo, referente a la disputa ítalo-abisinia, el cual salió a la luz el 7 de noviembre de 1935, representó otra muestra fehaciente de su alineamiento total con el régimen fascista. Mediante palabras fuertes y agresivas, el periodista criticó abiertamente la actitud del Gobierno de Cuba por haber emitido el Decreto Oficial 2487 por el cual, como miembro de la Sociedad de Naciones, se fijaba la fecha y se enumeraban los artículos o productos que no se podrían comercializar con Roma, implementándose así en el país las medidas sancionadoras que se le aplicarían internacionalmente a Italia ${ }^{34}$. De esta forma Cuba efectivizaba la decisión de los 50 países

32 José Ignacio Rivero, «Impresiones», Diario de La Marina [La Habana], 5 de septiembre, 1935, 1.

33 José Ignacio Rivero, «El paso dado por Italia», Diario de La Marina [La Habana], 3 de octubre, 1935, 3.

34 Este decreto fue publicado en la Gaceta Oficial el 17 de octubre de 1935, y a su vez fue derogado por otra disposición de igual tipo, exactamente la número 2890 , mediante la cual se ampliaba la lista de artículos y el material de guerra que se prohibía comerciar con Italia, y salió publicado en la Gaceta Oficial el 12 de diciembre de 1935. Secretaría de Estado, Cuba, Boletín Oficial de la Secretaría 
miembros de la Sociedad de Naciones que habían aprobado, a través del Consejo de la Liga de las Naciones, aplicar sanciones económicas y financieras al país agresor ya que «[...] el Gobierno italiano había empleado el recurso de la guerra lo cual era contrario al artículo $12 \mathrm{del}$ Pacto de Naciones» ${ }^{35}$.

Mediante este escrito, el cual llevó como título «¿Por qué precipitarnos?», Rivero en un primer momento afirmó que el gobierno cubano, al tomar esa medida, había actuado festinadamente al no tener en cuenta, por sobre todas las cosas, la histórica amistad que existía entre nuestro país y el Reino de Italia. Respecto a estos vínculos, ejemplificó al decir:

[...] nos hemos precipitado de este modo en un problema que afecta en lo más hondo a un país como Italia, que no nos ha regateado nunca las pruebas de amistad, desde los lejanos días que se puso generosamente a nuestro lado en la recia batalla que Cuba libraba por su libertad reconociendo antes que ninguna otra nación nuestra independencia, hasta días más recientes cuando a raíz de la caída de Grau San Martín, el enviado del Extraordinario y Ministro Plenipotenciario de su Majestad el Rey Víctor Manuel in fue el primer diplomático europeo que llevó al gobierno del Coronel Mendieta el testimonio de la sincera y explícita simpatía del Gobierno de Roma $[\ldots]^{36}$.

Más adelante, en un segundo momento de su extensa reflexión, el fiel seguidor de Mussolini defendió, como miembro legítimo de la burguesía cubana, los intereses económicos de esa clase social, los cuales, a su parecer, se habían puesto en peligro al dictar el Decreto Oficial que prohibía el comercio, prácticamente en su totalidad, con la nación infractora. $\mathrm{Al}$ respecto, comentó:

[...] Tememos mucho que, por las típicas características de la economía corporativa de un lado, y por nuestra precipitación del otro, nuestras futuras relaciones comerciales con Italia salgan gravemente dañadas, comprometiendo todas las gestiones hechas hasta ahora para asegurarnos en aquel país un mercado donde colocar, con todas las garantías que ofrece una economía disciplinada como la italiana, varios de

de Estado (La Habana: Imprenta y Papelería de Rambla, Bouza y Cía., 1935), 457-501.

35 Alfred Zimmern, «The League's Handling of the Italo-Abyssinian Dispute», International Affairs (Royal Institute of International Affairs 1931-1939), n. ${ }^{\circ} 6$ (1935): 751-768.

36 José Ignacio Rivero, «¿Por qué precipitarnos?», Diario de La Marina [La Habana], 7 de noviembre, 1935, 3. nuestros productos esenciales mientras Italia podría seguir enviándonos muchos productos de merecida fama, como algunos medicinales que -según estimados médicos cubanos-, constituyen una verdadera gloria de la moderna medicina italiana ${ }^{37}$.

Ciertamente, si analizamos con detenimiento la preocupación de Rivero, podríamos afirmar que esta formaba parte del andamiaje propagandístico que el régimen de Roma había diseñado en la búsqueda de simpatías y de aliados a raíz de la precaria situación económica y de bloqueo que enfrentaba. No era realmente una preocupación sana por los ingresos que podían dejar de ganar los comerciantes y empresarios cubanos, pues el mercado italiano era receptor, a diferencia del norteamericano, de productos muy específicos, como, por ejemplo, el tabaco, y su comercialización no fue restringida en la mencionada disposición ${ }^{38}$.

El tema de la posición asumida por Cuba y su adhesión al grupo de naciones sancionadoras fue una cuestión recurrente en las páginas del diario. Sin embargo, este asunto no siempre fue, sorprendentemente, abordado exclusivamente por intelectuales y periodistas nacionales. Desde septiembre de 1935 el suplemento comenzó a publicar con beneplácito, debido a la clara afiliación fascistoide de su contenido, las apreciaciones de algunos periodistas extranjeros en relación con el conflicto, entre los que se destacó el sueco Frederick Norman. La primera noticia que recibió y notició el periódico respecto a las concepciones y criterios que el periodista tenía referente a la disputa ítalo-etíope llegó a modo de cablegrama y reproducía, textualmente, una carta que él había dirigido a la Sociedad de Naciones mediante la cual proponía determinados remedios que, a su juicio, darían al traste con el recién malestar del mundo ${ }^{39}$.

37 Rivero, «¿Por qué precipitarnos?», 3.

38 Secretaría de Estado, Cuba, «Decreto 2890», Boletín Oficial de la Secretaría de Estado (La Habana: Imprenta y Papelería de Rambla, Bouza y Cía., 1935), 457-501.

39 Las proposiciones que hacía eran: 1) La concertación inmediata de un Pacto de No Agresión entre Alemania y Francia. 2) La cancelación de las deudas de guerra, medida que haría viable e ineludible la estabilización monetaria, indispensable para garantizar la seguridad económica de los pueblos. 3) La expulsión inmediata de China y de Etiopía de la S. de N. con derecho a volver a ser miembro tan pronto como hayan logrado reunir las condiciones esti- 
Precisamente, fue este «pacifista» devenido en redactor asiduo del diario habanero quien, en más de una ocasión, se refirió en sus comentarios a la actitud tomada por Cuba frente a las sanciones e hizo afirmaciones tendenciosas que pusieron en entredicho el prestigio y la justicia con que actuó el Presidente de la República, Carlos Mendieta Montefur. Según un artículo que se publicó el 22 de diciembre de 1935 y que llevó por nombre "Cuba ante el conflicto ítalo-etiópico», Norman afirmó que la postura del Gobierno cubano había estado condicionada por las promesas y ventajas comerciales que había hecho el Ministro de la Gran Bretaña acreditado en La Habana durante una visita privada que realizó con anterioridad a la Secretaría de Estado, y Cuba a cambio se había comprometido a no oponerse a las sanciones contra Italia. Unido a esto, refiriéndose al Presidente de Cuba, expresó:

[...] El confusionismo actual es consecuencia inevitable de la mediocridad que caracteriza a los principales estadistas de nuestra época, electos por sufragio universal en la mayor parte de los casos e impuestos por dictaduras en otros. [...] El sufragio universal constituye una injusticia tan tremenda como la que puede ser cualquier dictadura. Ojalá que el conflicto ítalo-etíope, y la posición asumida por $\mathrm{Cuba}$, sirva para abrir los ojos de los cubanos ante la necesidad de evitar tanto la democracia como la dictadura ${ }^{40}$.

A los dos días de la publicación de estas palabras, la Secretaría de Estado, en las propias páginas del diario, emitió una nota oficial en la que expresó, ante todo, su interés de hacer público su desacuerdo con las aseveraciones hechas por el ciudadano Norman y ratificó, además, que el Gobierno de Cuba había procedido a aplicar las sanciones única y exclusivamente en cumplimiento de sus obligaciones internacionales, solemnemente contraídas como Estado signatario del Covenant ${ }^{41}$.

Las opiniones de los representantes de la emigración italiana en Cuba seguidora de las ideas fascistas

puladas para ello. Tomado de: EFE, «Frederick Norman, propuesto para Premio Nobel, sugiere la expulsión de Abisinia y de China de la Sociedad de Naciones», Diario de La Marina [La Habana], 24 de septiembre, 1935, 22.

40 Frederick Norman, «Cuba ante el conflicto ítalo-etiópico», Diario de La Marina [La Habana], 22 de diciembre, 1935, 32.

41 Secretaría de Estado, «Nota Oficial de la Secretaría de Estado», Diario de La Marina [La Habana], 24 de diciembre, 1935, 1. disfrutaron también de un amplio espacio en el Diario de la Marina. Como bien se anunció anteriormente, el bloqueo económico que había articulado la Sociedad de Naciones como condena al Gobierno de Roma por la invasión a Etiopía exigió de este grupo de inmigrantes, y de la sección del Partido Fascista a la que pertenecían, redoblar los esfuerzos para levantar la moral de Italia $y$, sobre todas las cosas, sumar simpatizantes en todos los continentes. Precisamente, la totalidad de los artículos que publicaron en el diario estuvieron encaminados a exaltar los valores italianos y, por supuesto, ninguno de ellos dejó de legitimar las acciones que se llevaban a cabo en África. Uno de los primeros trabajos proveniente de este grupo que publicó el famoso periódico cubano fue escrito por Paolo Nicolai ${ }^{42}$ y llevó como título «Estos pobres etiópicos». Sin apartarse de los temas que abordaron sus colegas ya vistos, en una primera parte Nicolai atacó abiertamente a la población etíope, alegando que actualmente en ese país se vivía en la bestialidad, y que las condiciones de semibarbarie de «[...] esos pobres etiópicos [...]» frustraban, prácticamente, todo esfuerzo del poder central, por lo que era imposible alegar que Etiopía era un Estado al que había que respetar. Unido a esto, legitimó los derechos que tenía Italia sobre el país africano, alegando lo siguiente:

[...] Desde el lejano 1875 magníficas figuras de la ciencia y muchísimos otros más hicieron ofrendas de sus preciosas vidas para conquistar para Italia la primacía en la penetración en un inmenso territorio de África. [...] Vinieron años después las famosas expediciones militares cuyos rotundos fracasos, más que a la impericia de los generales o a la falta de entrenamiento de los soldados, se debieron a las nefastas pasiones políticas que dividían a los italianos, recién surgidos al rango de nación libre e independiente. Los que siguen ignorando la historia colonial deben saber que Italia tiene sobre Etiopía indiscutibles derechos adquiridos al precio de generosa sangre y amarga experiencia $[\ldots]^{43}$.

42 Paolo Nicolai ocupaba el cargo de asesor en la directiva de la Sociedad Ítalo-cubana de Cultura la cual fue creada por el Fascio de La Habana a finales de 1934, y era además la figura protagónica de La Voz de Italia, espacio radial que divulgaba, con un enfoque turístico aparentemente, los logros y valores del pueblo italiano. Para más información, consultar: Froilán González y Adys Cupull, Julio Antonio Mella y Tina Modotti contra el Fascismo, 197.

43 Paolo Nicolai, «Esos pobres etiópicos», Diario de La Marina [La Habana], 14 de julio, 1935, 30. Los «derechos históricos de Ita- 
En definitiva, las ideas sobre las cuales fue diseñada la maniobra propagandística de los seguidores del fascismo en La Habana coincidían cabalmente con el discurso político que día a día se pronunciaba desde la tierra del Littorio ${ }^{44}$. Unido a la defensa del derecho histórico que tenía el Reino de Italia sobre el de Etiopía, el autor en el mismo artículo esgrimió, como otro de los móviles importantes de la posición guerrera de su país, el temor que existía en los altos círculos políticos italianos de que otros países se apoderaran económica y políticamente del territorio abisinio, refiriéndose exactamente a los recientes vínculos comerciales contraídos entre Addis Abeba y Japón. Al respecto, comentó:

Deben saber también que lo que mueve a Italia no es tan solo el legítimo y natural deseo de borrar de su historia militar un desgraciado paréntesis, sino el fundado temor de que otros traten de recoger la cosecha sembrada por sus heroicos hijos. Las hábiles maniobras del Japón a las sombras del trono del Negus son una tangible prueba de que no andamos tan equivocados $[\ldots]^{45}$.

Otro de los asuntos que más trató en sus habituales comentarios fue lo referido al rol que desempeñó la Sociedad de Naciones como mediadora en el conflicto. En varios de sus manifiestos, el adepto fascista utilizó frases para referirse al organismo internacional como "garaje de pésimo gusto futurista» $\mathrm{y}$ «[...] las anémicas venas de la Liga» ${ }^{46}$.

lia sobre Etiopía» fueron uno de los ejes de la propaganda italiana para justificar el ataque $y$, por supuesto, todos los sectores que a nivel mundial aplaudieron la acción bélica se hicieron eco de esta idea, incluyendo la pequeña colonia italiana asentada en Cuba y un exiguo número de intelectuales y periodistas vinculados a esta. Según el gobierno italiano, los derechos italianos sobre Etiopía venían desde 1869 cuando la Compania di Navigazione Italiana Rubattino compra legalmente porciones de la bahía de Assab y Massawa, pasando por el Tratado de Ucciali en 1889, hasta llegar a la firma de acuerdos entre Inglaterra e Italia en los que reconocía a Abisinia como un hinterland italiano. Para más información, consultar: Societá Editrice di Novissima, Italia, Italia y Abisinia (Roma: Societá Editrice di Novissima, 1928), 24. Alexis Marcoff, Los 7.000 años de Etiopía, ensayo histórico del imperio abisinio (Barcelona: Casa Editorial Araluce, 1936), 210-216.

44 Símbolo de la antigua República romana que representaba la unidad y el poder del pueblo de Roma, y del que se apoderó el fascismo en su afán nacionalista. Para más información, ver: Franco Savarino. «Bajo el signo del 'Littorio'. La comunidad italiana en México y el fascismo (1924-1941)», Revista Mexicana de Sociología 64, n. 2 (abril-junio, 2002): 113-139.

45 Nicolai, «Esos pobres etiópicos», 30.

46 Paolo Nicolai, «¿Qué hará la Liga?», Diario de La Marina [La Habana] 21 de julio, 1935, 30.
De igual forma, en más de una ocasión justificó la actitud intransigente y poco conciliadora que mantuvo Mussolini ante todos los planes de paz que le propuso Inglaterra, aludiendo:

[...] sería un gravísimo error creer que, para salvar el quebrantado prestigio de la Liga, Italia pueda sacrificar sus intereses vitales que se sintetizan en la fórmula: expansión económica y efectiva seguridad colonial ${ }^{47}$.

El Diario de La Marina también publicó con beneplácito los comentarios de Guido Campilli, quien fuera el Secretario del Fascio de Cuba y uno de los profascistas más activos durante la invasión a Abisinia. A solo 24 horas de haberse iniciado la invasión a Abisinia desde Eritrea y la Somalia italiana por parte de las tropas del Duce, Campi1 li valoró la actitud de Mussolini en África como muy positiva, exaltando a su vez la situación política en la que se encontraba Italia, y comentó:

Italia, la nación sumisa de antaño ya no existe; es un estado poderoso y audaz que si no tiene la riqueza de Inglaterra y de Francia, posee la riqueza más preciada para un país, la voluntad inquebrantable de todo un pueblo que quiere vivir y trabajar libre y decorosamente, y no morir de anemia en un territorio desproporcionalmente para sus necesidades $[\ldots]^{48}$.

A simple vista se nota que las ideas que defendió Guido Campilli como representante de la comunidad italiana profascista en La Habana estaban encaminadas, una vez más, a respaldar las líneas discursivas del régimen de Roma. Sin ningún tipo de respeto, y hasta recurriendo a mentiras y tergiversaciones de la realidad italiana y etíope, el Fascio y sus integrantes trataron de hacer ver la agresión como un hecho lícito. En un segundo momento de su artículo, el furibundo fascista intentó sensibilizar a la opinión pública cubana al extrapolar a Cuba la supuesta necesidad que tenía Italia de tierras preguntando:

[...] ¿Qué haría Cuba si tuviera (haciendo la debida proporción) 31 millones de habitantes? ¿Se conformarían los cubanos con vivir encerrados en su isla, sin

\footnotetext{
47 Paolo Nicolai, «Por qué Italia rechazó el plan», Diario de La Marina [La Habana] 24 de septiembre, 1935, 22.

48 Guido Campilli, «Los imperialismo europeos», Diario de La Marina
} [La Habana] 4 de octubre, 1935, 22. 
esperanza alguna, cuando tierras inmensas y fértiles quedasen en el continente americano sin provecho alguno para nadie? ¿Aceptaría que la Sociedad de $\mathrm{Na}$ ciones Americanas, por medio de los Estados Unidos, les concediera a título de beneficencia, y para taparle la boca, Cayo Hueso y las ciénagas adyacentes? ${ }^{49}$.

Por último, es importante destacar la cobertura informativa y el apoyo que le brindó el periódico a todas las actividades que durante ese periodo realizaron el Fascio y la Sociedad Ítalo-Cubana de Cultura como los máximos mensajeros del ideal fascista en Cuba. Por si fuera poco, muchos de los periodistas que asiduamente reportaban para el diario y llevaron muy cerca el desarrollo de la cuestión ítalo-etíope, como el ya citado Juan Luis Martín, protagonizaron muchas de estas actividades, lo que demuestra la estrecha relación existente entre el diario y la comunidad profascista asentada en la isla. Por ejemplo, el 22 de octubre de 1935, el rotativo en una de sus páginas sociales reportó con énfasis lo siguiente:

El pasado domingo en la sede social del Fascio se llevó a cabo una magnífica manifestación de alta cultura con la magistral conferencia de nuestro compañero Juan Luis Martín. [...] Inició el acto el profesor Guido Campilli, quien puso de relieve, con palabras atinadas, la propaganda internacional en virtud de las que se trata de pintar a Etiopía como modelo de país libre, civilizado e independiente. El distinguido profesor concluyó dando al orador designado, Sr. Juan Luis Martín, las más expresivas gracias por haber accedido a la invitación $[\ldots]^{50}$.

El propio reportaje, al referirse a la intervención del letrado Martín, apuntó:

[...] Dos horas duró la conferencia [...]. Se extendió nuestro compañero sobre los caracteres más universales del problema [...]. Entrando de lleno en el problema, el conferenciante hizo un verdadero alarde de conocimientos sobre el desarrollo del problema colonial africano, de las rivalidades de las potencias. [...], se refirió a los motivos de la actitud de Italia, declarando cómo por los tratados con Inglaterra y con la misma Abisinia, el Gobierno de Roma posee derechos que no han prescripto aunque no se hayan ejercido en los últimos años; y los de la Gran Bretaña, que no cree altruista, sino en defensa de intereses imperiales, para cuya defensa intenta valerse de la Sociedad de Nacio- nes [...]. El conferencista cosechó con su sabiduría y exquisitez expositiva entusiastas aplausos ${ }^{51}$.

Paradójicamente, en la medida que las tropas italianas fueron ganando terreno en el campo de batalla, y la atención periodística se vio obligada a centrar su atención en asuntos de mayor importancia y trascendencia para el mundo como la remilitarización de la zona de Renana, el Diario de La Marina prestó menos atención a la evolución del conflicto ítalo-etiópico, aunque nunca dejó de reseñar las victorias, y, por supuesto, la entrada de las huestes fascistas en Addis Abeba en mayo de 1936.

En julio de ese mismo año, el inicio de la Guerra Civil española ocupó todos los espacios noticiosos de la isla, lo que hizo que gradualmente fueran desapareciendo las noticias referentes a Etiopía. No será hasta 1941, al calor del desarrollo de la Segunda Guerra Mundial, que Abisinia y las acciones de reconquistas de Hailé Selassié volverán a ser motivo de comentarios en las controvertidas páginas.

\section{Conclusiones}

Sin lugar a dudas, según lo expuesto, se puede afirmar que la sociedad cubana realmente no mostró mucho interés por lo que aconteció en África ya que por ese entonces se hallaba sumergida en la búsqueda de soluciones para sus problemas internos. Más allá de eso, hubo voces que se alzaron aunque fueron muy reducidas, $y$ los alineamientos asumidos estuvieron circunscritos básicamente a los disímiles pronunciamientos de determinados intelectuales en los medios de prensa escrita.

Aunque existieron publicaciones y voces que criticaron abiertamente al fascismo y abogaron por Abisinia, fueron los criterios favorables a Roma los más difundidos y, a su vez, los que mayor resonancia alcanzaron. Si la agresión italiana a Etiopía fue apoyada desde Cuba fue debido al quehacer de algunos miembros de la pequeña colonia italiana asentada en La Habana y de un reducido grupo de intelectuales comprometidos con esta.

49 Campilli, «Los imperialismo europeos», 22.

50 Editorial, «Juan Luis Martín disertó acerca del problema etiópico», Diario de La Marina [La Habana] 22 de octubre, 1935, 3.

51 Editorial, «Juan Luis Martín», 3. 
Aprovechando la solvencia económica que disfrutaba la emigración y la intelectualidad que comulgaba con Roma, estos sectores utilizaron los medios de comunicación más poderosos del momento e hicieron de ellos portavoces de sus opiniones. Las notas de prensa y comentarios aparecidos en el Diario de La Marina, órgano cubano y conservador por excelencia, dan fe de los estrechos vínculos existentes entre la comunidad italiana favorable al fascismo y algunos de los intelectuales que integraban la derecha cubana. Esto los incluye en la larga lista de intelectuales y periódicos que a lo largo de toda Latinoamérica siguieron las directrices del partido fascista en la búsqueda de apoyo a la acción colonizadora.

\section{Bibliografía}

\section{Fuentes bibliográficas}

Anuario Diplomático y Consular de la República de Cuba (viI). La Habana: Cultural S.A, 1940.

Bertaux, Pierre. África, desde la prehistoria hasta los Estados actuales. Historia Universal Siglo XXI. Madrid: Ediciones Castilla, S.A, 1972.

Entralgo, Armando. África. Ciudad de La Habana: Editorial Pueblo y Educación, 1980.

Frenkel, M. Yu. «Ítalo-Ethiopian War of 19351936 and the attitude to it of the progressive European public (as reflected in the journal "Negro Worker"». En Anti-colonialism and democratic traditions in Europe: African Aspect, 147-160. Bratislava: Institute of Historical Studies of the Slovak Academy of Sciences, 1985.

González, Froilán y Adys Cupull. Julio Antonio Mella y Tina Modotti contra el Fascismo. Ciudad de La Habana: Casa Editora Abril, 2005.

López Civeira, Francisca. «El cambio histórico». En Cuba y su historia, 117-216. Ciudad de La Habana: Editorial Félix Varela, 2005.

Marcoff, Alexis. Los 7.000 años de Etiopía, ensayo histórico del imperio abisinio. Barcelona: Casa Editorial Araluce, 1936.

Oficina Nacional de Estadísticas, Cuba. Los censos de población y viviendas en Cuba. Censos del periodo 1907-1953. Ciudad de La Habana: Oficinal Nacional de Estadísticas, 2007.

Ortega y Gasset, Eduardo. Etiopia: el conflicto ItaloAbisinio. Madrid: Imprenta de Juan Pueyo, 1935.
Secretaría de Estado, Cuba. Boletín Oficial de la Secretaría de Estado. La Habana: Imprenta y Papelería de Rambla, Bouza y Cía., 1935.

Societá Editrice di Novissima, Italia. Italia y Abisinia. Roma: Societá Editrice di Novissima, 1928.

\section{Fuentes publicísticas}

Albert, Jesús. «Las relaciones entre los fascismos y el movimiento nacionalista árabe». Revista de Estudios Internacionales Mediterráneos (REIM), n. ${ }^{\circ}$ 6 (2008): 53-77.

Alpert, Michael. «La conquista de Abisinia». Historia 16, n. ${ }^{\circ} 354$ (2005): 37-47.

Baudendistel, Rainer. «La fuerza frente al derecho: el Comité Internacional de la Cruz Roja y la guerra química en el conflicto ítalo-etíope de 1935-1936». Revista Internacional de la Cruz Roja, n.o 145 (1998): 89-114.

Savarino, Franco. «Apuntes sobre el fascismo italiano en América Latina (1922-1940)». Reflejos, n. .9 (2000-2001): 100-110.

Savarino, Franco. «Bajo el signo del 'Littorio'. La comunidad italiana en México y el fascismo (1924-1941)». Revista Mexicana de Sociología 64, n. .2 (abril-junio, 2002): 113-139.

Scarzanella, Eugenia. «Cuando la patria llama: Italia en guerra y los inmigrantes italianos en Argentina». Nuevo Mundo Mundos Nuevos. http:// nuevomundo.revues.org/3735

Zimmern, Alfred. «The League's Handling of the Italo-Abyssinian Dispute». International Affairs (Royal Institute of International Affairs, 19311939), n. ${ }^{\circ} .6$ (1935): 751-768.

\section{Fuentes periódicas}

[Editorial]. «Juan Luis Martín disertó acerca del problema etiópico». Diario de La Marina [La Habana], 22 de octubre, 1935, 3.

[Editorial]. «Sociedades Españolas». Diario de La Marina [La Habana], 19 de febrero, 1936, 8.

[Editorial]. «Un acto cívico a favor de Abisinia en el Club Atenas». Diario de La Marina [La Habana], 5 de noviembre, 1935, 3 .

[EFE]. «Diez millones de hombres, mujeres y niños acudirán prestos a la llamada tradicional en defensa de la Patria». Diario de la Marina [La Habana], 3 de octubre, 1935, 22. 
[EFE]. «Frederick Norman, propuesto para Premio Nobel, sugiere la expulsión de Abisinia y de China de la Sociedad de Naciones». Diario de La Marina [La Habana], 24 de septiembre, 1935, 22.

[EFE]. «Las gestiones fracasarán en caso de no llegarse a un acuerdo durante la semana entrante, según ingleses». Diario de La Marina [La Habana], 18 de agosto, 1935, 28.

$[\mathrm{EFE}]$. «Muerte a un funcionario colonial francés en Djiboutí». Diario de La Marina [La Habana], 22 de enero, 1935, 22.

[EFE]. «Niegan avance en las negociaciones entre Italia y Abisinia». Diario de La Marina [La Habana], 14 de abril, 1935, 7 .

Campilli, Guido. «Los imperialismos europeos». Diario de La Marina [La Habana], 4 de octubre, 1935, 22.

Castañeda, Tiburcio. «Italia despliega actualmente una actividad guerrera». Diario de La Marina [La Habana], 7 de mayo, 1935, 20.

Martín, Juan Luis. "Actualidad Internacional». Diario de La Marina [La Habana], 6 de julio, 1935, 22.

Martín, Juan Luis. «Actualidad Internacional». Diario de La Marina [La Habana], 6 de agosto, 1935, 22.

Nicolai, Paolo. «¿Qué hará la Liga?». Diario de La Marina [La Habana] 21 de julio, 1935, 30.

Nicolai, Paolo. «Esos pobres etiópicos». Diario de La Marina [La Habana], 14 de julio, 1935, 30.

Nicolai, Paolo. "Por qué Italia rechazó el plan». Diario de La Marina [La Habana], 24 de septiembre, 1935, 22.
Norman, Frederick. "Cuba ante el conflicto ítaloetiópico». Diario de La Marina [La Habana], 22 de diciembre, 1935, 32.

Rivero, José Ignacio. «¿Por qué precipitarnos?». Diario de La Marina [La Habana], 7 de noviembre, 1935, 3.

Rivero, José Ignacio. «El paso dado por Italia». Diario de La Marina [La Habana], 3 de octubre, 1935, 3.

Rivero, José Ignacio. «Impresiones». Diario de La Marina [La Habana], 5 de septiembre, 1935, 1.

Secretaría de Estado. «Nota Oficial de la Secretaría de Estado». Diario de La Marina [La Habana], 24 de diciembre, 1935, 1.

\section{Fuentes de archivo}

Archivo Nacional de Cuba. «Manifiesto impreso del Partido Comunista de Cuba, firmado por el Comité Central referente al ataque del imperialismo italiano al pueblo abisinio». Fondo Especial, Legajo 1, Expediente 53.

Fecha de recepción: 12 de septiembre de 2013

Fecha de evaluación: 17 de noviembre de 2013

Fecha de aprobación: 10 de diciembre de 2013

\section{Cómo citar este artículo}

Consuegra Sanfiel, Alberto. «Cuba: el Diario de La Marina, los "misioneros de Mussolini” y la intelectualidad cubana proitaliana durante el segundo conflicto ítalo-abisinio (1935-1936)». Memoria y sociedad 18, n.o 36 (2014): 14-28. http://dx.doi. org/10.11144/Javeriana.MYS18-36.cdlm 